\title{
EL ALTAR DEL HOLOCAUSTO Y EL ARCA DEL TESTIMONIO EN EL APOCALIPSIS: RELACIONES MEDULARES PARA LA DOCTRINA DEL SANTUARIO EN LA TEOLOGÍA ADVENTISTA
}

\author{
Raúl A. Quiroga
}

\section{Introducción}

La doctrina del santuario establece, fundamenta, estructura y sustenta el sistema teológico bíblico adventista. ${ }^{1} \mathrm{El}$ ministerio sacerdotal oficiado en el santuario israelita se realizaba en torno a dos puntos focales, el altar del holocausto, eje del ministerio diario, y el arca del pacto, foco del ministerio anual o Día de la Expiación. Ambos ministerios eran realizados por el sumo sacerdote en ejercicio.

Una relación temporal se da con respecto del tiempo del cumplimiento del suceso señalado por el ministerio profético sacerdotal. Otra relación espacial se evidencia con relación al lugar, persona o sujeto profético que habría de ser el cumplimiento del suceso señalado por el ministerio profético sacerdotal.

El apóstol Pedro sugiere este esquema temporal, espacial y referido siempre a un sujeto profético.

Los profetas que profetizaron de la gracia destinada a vosotros, inquirieron y diligentemente indagaron acerca de esta

${ }^{1}$ Véase un bosquejo de esta importancia histórica, profética y teológica en Juan Víctor Mamani Quispe, "Desarrollo histórico de la doctrina del santuario", Evangelio 3, no. 1 (2010): 127-34. 
salvación, escudriñando qué persona [sujeto profético] y qué tiempo [tiempo y espacio] indicaba el Espíritu de Cristo que estaba en ellos, el cual anunciaba de antemano los sufrimientos de Cristo, y las glorias que vendrían tras ellos (1 P 1:10, 11).

En el modelo arquitectónico y estructural del santuario, en el que se percibe una relación geométrica y geográfica de las áreas santa y santísima, se percibe la relación teológica con respecto de dos mobiliarios centralmente geográficos en el santuario: (1) el altar del holocausto, colocado en el atrio y afuera del santuario mismo; y (2) el arca del testimonio colocada en el punto focal más interior, o el lugar más íntimo del santuario o tabernáculo mismo: el lugar santísimo. ${ }^{2}$

El altar del holocausto representa el lugar geográficoespacial-temporal del sacrificio, o el área en la que se hacía efectivo el perdón de los pecados y la justificación del pecador arrepentido. Esta parte del ritual se refiere a la expiación diaria o ministerio diario del sumo sacerdote. ${ }^{3}$

$\mathrm{El}$ arca del testimonio, en la que se guardaban las tablas de los diez mandamientos, representa el lugar geográfico, espacio-temporal o área en la que se constataba la vigencia, perpetuidad y obligación de la ley de Dios. Es el lugar que representa la obediencia y la santificación del pecador que ha recibido el perdón en el altar. ${ }^{4}$ Esta parte secuencial

Véanse Raúl Quiroga, "El santuario es el lugar", DavarLogos 10, no. 2 (2011): 174-6 y Ribamar Diniz, "El santuario y su precursor”, Evangelio 3, no. 1 (2010): 99-105.

${ }^{3}$ Raúl Quiroga, "El binomio altar/sacrificio como centro teológico del Pentateuco y su significado y simbolismo para el Nuevo Testamento", en Volviendo a los orígenes: Entendiendo el Pentateuco, ed. Merling Alomía, et al. (Lima: Universidad Peruana Unión, 2006), 375-88.

${ }^{4}$ Una santificación que apunta a una santidad no esencial sino relacional. Véase Terence E. Fretheim, The Pentateuch (Nashville: Abingdon 
del ritual se refiere a la expiación anual o ministerio anual del sumo sacerdote. En el Día de la Expiación se hacía efectiva una purificación, justificación, limpieza, expiación a favor del santuario, y en segunda instancia para todo Israel. Se ilustra lo expresado anteriormente en la figura 1.

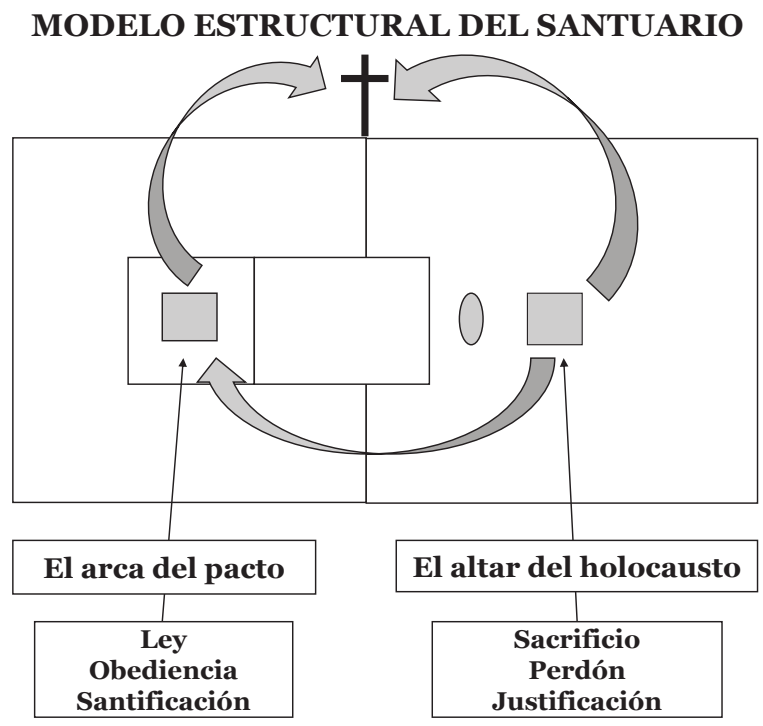

Figura 1

Una representación teológica de los focos espaciales del santuario podría incluir un movimiento en el espacio y en el tiempo desde el altar hasta el arca del testimonio, realizado por el personaje central del santuario: el sumo sacerdote. ${ }^{5}$ Es la persona que le da sentido a todo el sistema sacri-

Press, 1996), 133-35.

${ }^{5}$ Por lo menos la ceremonia convocaba a todo Israel. Véase Gerald Klingbeil, "Who Did, What and Why'. The Dynamics of Ritual Participants in Leviticus 8 and Emar 369", en Inicios, paradigmas y fundamentos: Estudios teológicos y exegéticos en el Pentateuco, Serie monográfica de 
ficial, ritual y ceremonial realizado en el espacio y en el tiempo programados para esta actividad realizada diaria y anualmente en el área del santuario. ${ }^{6}$

En un área profético-teológica se encuentra el lugar santo: incluye el sacrificio continuo y constante (תָּמִ (תמיד), la sangre expiatoria, el ministerio diario, emblema del perdón particular y personal, la justificación y la conversión.

En la otra área profético-teológica se ubica el lugar santísimo: incluye también un sacrificio, la sangre expiatoria, el ministerio anual, emblema del perdón colectivo y universal, la obediencia a la ley, la santificación y una voluntad puesta para siempre de parte del pacto (בְּרִית). Véase la figura 2 para tener una idea espacial de estas representaciones teológicas.

Estudios Bíblicos y Teológicos de la Universidad Adventista del Plata 1, ed. Gerald Klingbeil (Libertador San Martín, Entre Ríos, Argentina: Editorial Universidad Adventista del Plata, 2004), 118. No es muy común encontrar desarrollos sobre el ministerio sumo sacerdotal. Una excepción es el espacio dedicado a la misión y función del sumo sacerdote en Frank B. Holbrook, "The Israelite Sanctuary", en The Sanctuary and the Atonement: Biblical, Theological and Historical Studies, ed. Arnold V. Wallenkanpf, et al. (Collegedale, TN: College Press, 1989), 20-4. Dentro de la teología adventista, M. L. Andreasen intentó bosquejar la función sumo sacerdotal. Véase M. L. Andreadsen, The Sanctuary Service (Washington DC: Review and Herald, 1937), 45-58.

${ }^{6}$ Las dimensiones de espacio y tiempo son categorías propias de los significados tipológicos del santuario. Véase Richard Davidson, "Understanding Sanctuary Typology in Revelation”, en Symposium on Revelation, Daniel and Revelation Committee Series 6, ed. Frank B. Holbrook (Hagerstown, MD: Review and Herald, 1992), 105. 


\section{REPRESENTACIONES TEOLÓGICAS DE LOS FOCOS ESPACIALES DEL SANTUARIO}

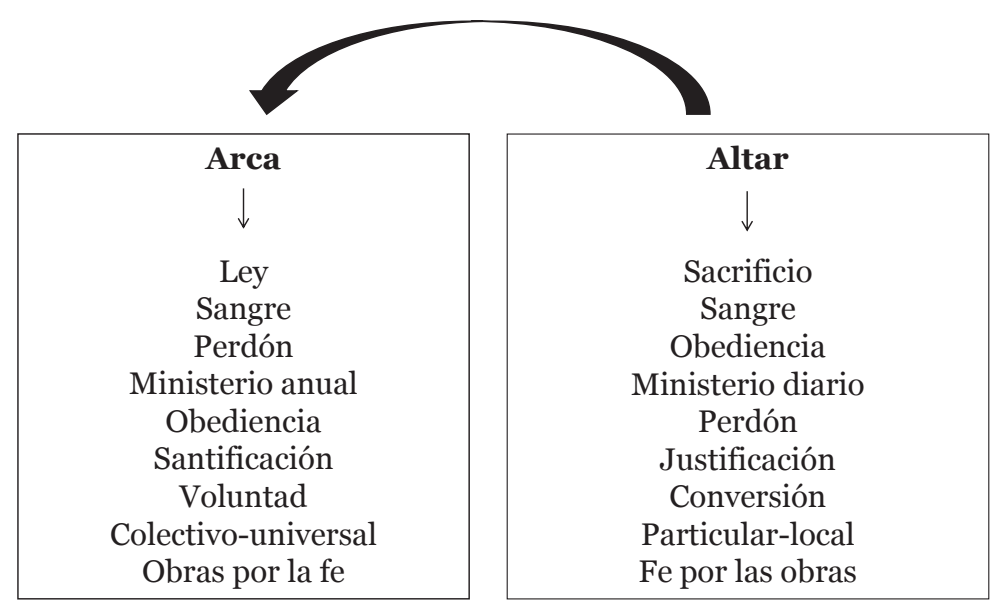

Figura 2

La representación teórica y teológica de los dos focos espaciales centrales del área del santuario se indica a través del ministerio diario y del ministerio anual del sumo sacerdote, cada uno representando instancias de la salvación (expiación, redención) en beneficio del pecador arrepentido (ministerio diario) y en beneficio de Israel (ministerio anual).

La historia de la Biblia (historia de la redención, de la salvación o de la cruz) relata que los personajes bíblicos escogidos por Dios para conducir la historia de Israel (o para hacerla volver a su curso con relación al santuario y su calendario profético de fiestas) siguieron el modelo teológico marcado por los espacios y los tiempos proféticos representados en el ministerio diario y anual del sumo sacerdote en el santuario israelita.

Incluso los patriarcas Adán, Noé y Abraham, que podrían ser exceptuados del esquema soteriológico histórico- 
profético por no pertenecer a la dispensación del santuario terrenal, predicaron y profetizaron en torno a los altares que edificaron, concientes de la perpetuidad de ley de Dios y de su responsabilidad pactual respecto de ella. El sacrificio sobre el altar patriarcal concretizaba el concepto soteriológico de salvación por sustitución.

En la siguiente tabla, se mencionan personajes bíblicos que tuvieron en consideración el eje teológico de la salvación representado en el altar del sacrificio.

\begin{tabular}{|c|l|}
\hline \multicolumn{2}{|c|}{ Historia de la redención } \\
\hline Personajes & \multicolumn{1}{c|}{ Altar/sacrificio } \\
\hline AT & $\begin{array}{l}\text { Adán, Noé, Abraham, Moisés, Josué, Samuel, } \\
\text { David, Salomón, Elías, Ezequías, Josías, Jo- } \\
\text { sué, Zorobabel, Esdras y Nehemías }\end{array}$ \\
\hline NT & $\begin{array}{l}\text { Jesús es la realidad última del esquema altar/ } \\
\text { sacrificio incluyendo las evidencias presenta- } \\
\text { das por Juan, Pedro y Pablo }\end{array}$ \\
\hline
\end{tabular}

Se mencionan también personajes bíblicos que tuvieron en consideración el eje teológico de la salvación representado en el arca del testimonio. Con respecto a los patriarcas se puede hacer la misma observación que se hizo para el cuadro anterior: edificaron sus altares, ofrecieron sus sacrificios siendo concientes de la vigencia de la ley de Dios en sus vidas. Tenían esa ley escrita en sus mentes y grabada en sus corazones (Pr 3:1-3; Jer 31:33). Sacrificio y ley se concretizaban y se evidenciaban en su experiencia de adoración del Dios verdadero. Véase la siguiente tabla. 


\begin{tabular}{|c|c|}
\hline \multicolumn{2}{|c|}{ Historia de la redención } \\
\hline Personajes & Arca/ley \\
\hline AT & $\begin{array}{c}\text { Adán, Noé, Abraham, Moisés, Josué, Samuel, } \\
\text { David, Salomón, Elías, Ezequías, Josías, } \\
\text { Josué, Zorobabel, Esdras y Nehemías }\end{array}$ \\
\hline NT & $\begin{array}{c}\text { Jesús es la realidad última del esquema arca/ } \\
\text { ley. Jesús es la encarnación de la ley, el Verbo } \\
\text { hecho carne (Jn 1:14; Heb 8:10; 10:16) }\end{array}$ \\
\hline
\end{tabular}

Se nota que Jesús pasa a ser el personaje bíblico en el que el sacrificio del altar y el arca de la ley se hacen realidad. En la persona y ministerio de Jesús tienen su cumplimiento perfecto (Heb 8-10).

\section{El altar del holocausto en el Apocalipsis}

El Apocalipsis es el libro del NT que más veces usa la palabra “altar” (8x). Levítico es el libro que más veces la usa en toda la Biblia. La ambientación del santuario es evidente en Apocalipsis a través del término "altar". No se registra la palabra "sacrificio" en el Apocalipsis. Tampoco la palabra "ofrenda".

Dado que Apocalipsis es un libro profético-simbólico, sustenta en sí mismo una elipsis de términos que obliga a una exégesis por omisión. En lugar de "sacrificio" u "ofrenda" figura el término "altar" $(6: 9 ; 8: 3,5 ; 9: 13 ; 11: 1 ; 14: 18 ; 16: 7)$ que es una referencia al lugar santo del santuario terrenal. Pero de todas maneras están representados en Apocalipsis los elementos del sacrificio. Por ejemplo, la palabra "cordero", relacionada con el altar de los sacrificios, se usa más veces en Apocalipsis (29x) que en todos los libros de la Biblia. Otra palabra contextual con el altar, "sangre", se usa 436 veces en la Biblia. Donde más veces aparece es en Levítico (87x). Solo la Epísto- 
la a los Hebreos (22x) supera a Apocalipsis (19x) en el NT.

También el término "fuego", se usa un total de 483 veces en la Biblia, relacionado más que nada con los libros referidos al santuario y a los sacerdotes. "Fuego" se usa más veces en el AT que en el NT pero el Apocalipsis se inserta en la lista como el libro del NT con más referencias.

Los términos "incienso" o "incensario" son muy usados en el AT con relación al santuario y al ministerio sumo sacerdotal. En Apocalipsis "incienso" aparece en 8:3, 5, e "incensario" en 8:3, 4; 18:13. Hay mucho incienso en el incensario de Apocalipsis. Es un libro aromatizado con el olor del santuario. Incensario e incienso son una referencia al ministerio diario y anual del sumo sacerdote.

\section{El arca del testimonio en el Apocalipsis}

El término "arca" aparece más veces en los libros propios de la temática del santuario, y en esta secuencia: 1 Crónicas, Éxodo, Deuteronomio, Números. En el NT, se usa solo en Heb 9:4 y en Ap 11:19.

La palabra "trompeta" se usa más veces en 2 Crónicas en el AT y en Apocalipsis en el NT (1:10; 4:1; 8:2, 6, 13; 9:14). Las trompetas se usan en circunstancias bélicas (Josué y Jeremías) y en cultuales de adoración (Levítico y Números), pero más relacionada con las fiestas solemnes del santuario que con las guerras. Este uso del término indica una ambientación del santuario en el Apocalipsis.

La palabra "ángel" se usa más veces en el Apocalipsis que en cualquier otro libro de la Biblia (53x de 197x). No se usa esta palabra con relación al santuario en el AT aunque sí en el NT. La palabra "querubín”, relacionada con el arca del santuario, no se usa en el Apocalipsis. Se usa más veces en Ezequiel y solo en Hebreos 9:5 en el NT. Es una mención muy exclusiva referida a los querubines del lugar santísimo del ta- 
bernáculo y del templo (Éxodo, 1 Reyes, 2 Crónicas y Salmos). También es una referencia a los querubines celestiales. Este término tiene una familiaridad semántica con "ángel” y genera una relación con el santuario en Apocalipsis.

La palabra "ley" nunca se usa en Apocalipsis pero tiene una íntima relación con las palabras "mandamiento", "testimonio" y "arca" (Dt 31:9, 26; Esd 10:3; Sal 19:7; 78:5; Is 8:16, 20; Jn 8:17; Hch 22:12; Ro 7:8-9, 12; Heb 7:5, 16; 10:28). "Mandamiento" es propio de Salmos y Deuteronomio en el AT y de 1 Juan y Juan en el NT. En Apocalipsis se usa solo 2 veces $(12: 17 ; 14: 12)$. "Testimonio" en plural se refiere a las instrucciones de Dios dadas a Israel (Sal 119) y en singular suele referirse a los diez mandamientos (Éx 31:18; 32:15; 34:29). Se registra en Ap 1:9; 6:9; 12:11, 17; 15:5; 19:10; $20: 4$. "El tabernáculo del testimonio" se reconoce en Ap 13:6 y 21:3. "Pacto" se usa en Ap 11:19 y es también una referencia a los diez mandamientos como el contenido del pacto (Éx 34:28; Dt 4:13; 7:9; 9:9, 11, 15; Neh 1:5; Sal 103:18; Dn 9:4).

La palabra "templo" en Apocalipsis es naos (gr.) y se usa más en este libro que en cualquier otro. No se usa en Apocalipsis la palabra griega clásica para "santuario" (hagion).

Hay también una serie de adjetivos numerales cardinales con sus correspondientes ordinales que generan una ambientación con el santuario en Apocalipsis: "número", “diez", "décimo", "cuatro", "cuarto", "seis", "sexto", "siete", "séptimo". Las cantidades ordinales y sus secuencias cardinales se refieren a distintas entidades como ángeles, iglesias, espíritus, candeleros, estrellas, sellos, cuernos, ojos, trompetas, truenos, cabezas, diademas, plagas, copas, reyes.

Otros sustantivos propios de Apocalipsis, como "palabra”, "eterno", "sello", "trono", "hombre", "gloria", "honra", "imagen", "cielo y tierra", "mar y las fuentes de las aguas", son términos que hacen alusión al santuario y a la ley de Dios contenida allí. 


\section{Exégesis por omisión en el Apocalipsis}

La carencia de ciertos términos esperados en el Apocalipsis dada su temática, impone o sustenta en sí mismo, por su condición de libro profético-simbólico, una elipsis de términos que obliga a una exégesis por omisión. Por ejemplo, en lugar de "ley" o "tablas" se encuentran las expresiones "arca de su pacto se veía en su templo" (11:19), "mandamientos" (12:17; 14:12) o "templo del tabernáculo del testimonio" (15:5). Son términos relacionados con el arca del testimonio ubicada en el lugar santísimo del santuario terrenal. El estudio terminológico muestra que hay una ambientación del santuario en el libro de Apocalipsis a pesar de una elipsis estratégica y programada.

\section{El sumo sacerdote como eje central del ministerio redentor y expiatorio prefigurado en el santuario terrenal}

Como ya se expresó anteriormente, el eje funcional y estructural del servicio expiatorio del santuario en última instancia no es la estructura o el mobiliario del santuario en sí sino la persona que le da sentido a todo ese esquema ritual, funcional, expiatorio y ministerial del santuario: el sumo sacerdote. Las consideraciones espaciales y temporales del ministerio expiatorio del sumo sacerdote en el santuario terrenal sobre la base de la relación espacio-temporal entre el altar y el arca, determinan que todo el servicio del santuario deba ser: (1) Soteriológico: Condiciona la salvación de los seres humanos. (2) Profético: Señala los eventos, los lugares y las personas en los que se cumplirían las profecías señaladas espacial y temporalmente en el ministerio sumo sacerdotal del santuario terrenal. La persona que oficia en el santuario conduce y le da sentido a la historia (espacio, tiempo y sujetos proféticos). (3) Escatológico: Señala 
a un futuro lejano, al final de los tiempos. (4) Expiatorio: Soluciona el problema del pecado.

El espacio que ocupa esa persona (sumo sacerdote) para realizar su ministerio se vuelve un espacio profético pues ella misma es una persona profética. Igualmente, el tiempo que emplea para realizar su ministerio se torna en un tiempo profético. Estos espacios y tiempos proféticos están dados por una estrecha y común relación temporal entre el altar y el arca. Estas afirmaciones se representan en la figura 3.

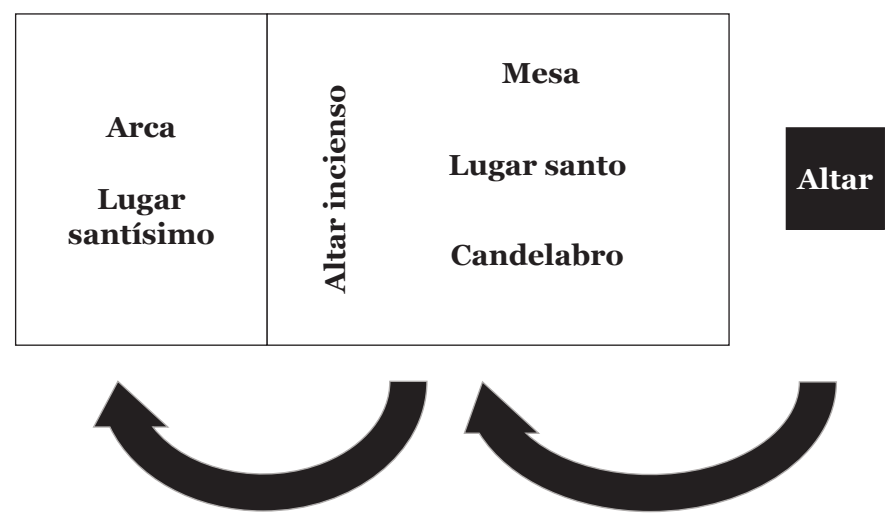

Figura 3

\section{La relación espacio-tiempo proféticos representados en el calendario anual de fiestas del santuario israelita}

En el calendario anual profético del santuario del AT, los tres kairós (gr.) o mo’ed (heb.) se referían a los tres viajes o momentos festivos (Éx 23:14; Dt 16:16) sumando un total de siete jag (heb.). Al principio del año durante la primavera, se celebraban las fiestas del comienzo del año ritual: (1) Pascua, (2) Panes sin levadura, (3) Primicias y, finalmente, (4) Pentecostés, 50 días después de la Pascua. Al fin del año, 
durante el otoño, se celebraban las fiestas del fin del año ritual: (5) Fiesta de la Trompetas o del Año Nuevo, 7 (6) Día de la Expiación y (7) Fiesta de los Tabernáculos o Cabañas. Esos tres kairós o mo'ed, sumaban siete jag en un tiempo determinado y cronometrado (cronos, gr.) según Lv 23.

Fiestas del comienzo del año: (1) Pascua (Pésaj), 14º Nisán o primer mes llamado también Abib (2) Panes sin Levadura (Matsot), $15^{\circ}$ de Nisán, (3) Primicias (Bikkurim) (4) Pentecostés, siete semanas después de la Pascua (Shevuot).

Fiestas del fin del año: (5) Fiesta de las Trompetas (Rosh Hashanah), $1^{\circ}$ día de Tishri, séptimo mes (6) Día de la Expiación (Yom Kippur), $10^{\circ}$ día del $7^{\circ}$ mes y (7) Fiesta de los Tabernáculos (Sukot), $15^{\circ}$ de Tishri, séptimo mes. Exponemos el calendario anual de las fiestas del santuario israelita en la figura 4.

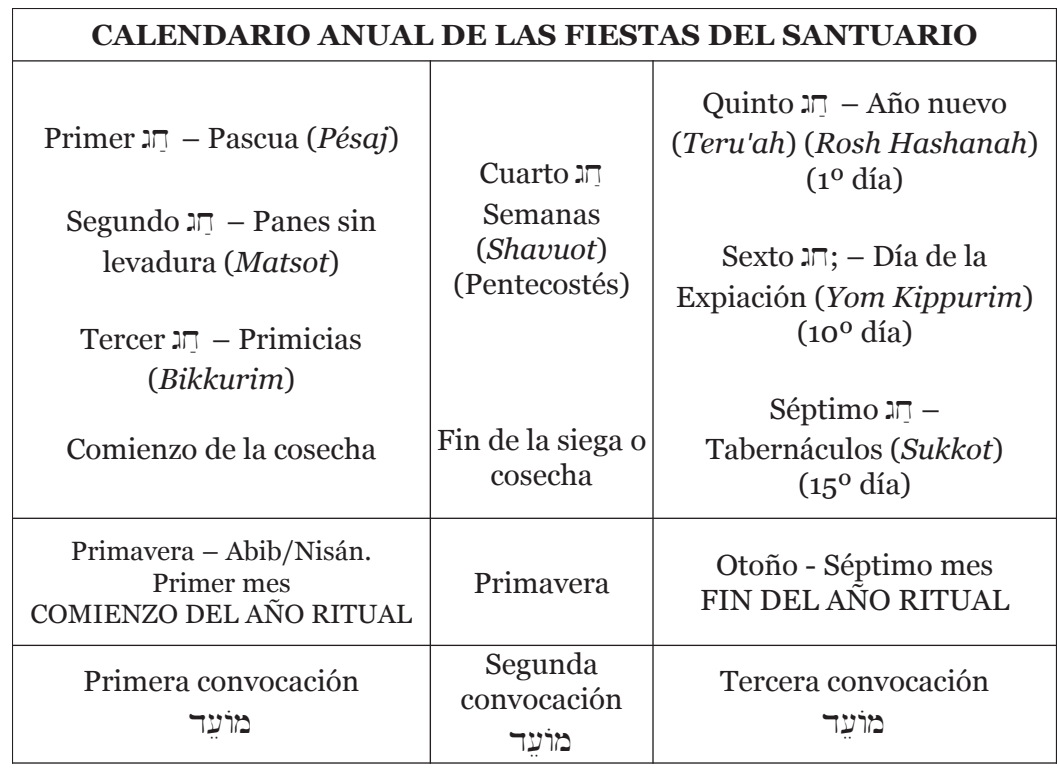

Figura 4

${ }^{7}$ Hoy denominado Rosh Hashannah (comienzo del año, año nuevo). 
El calendario profético anual del santuario terrenal era una representación del extenso calendario escatológico del santuario celestial. Cristo fue nuestra Pascua (1 Co 5:7) y la iglesia cristiana naciente tuvo su Pentecostés (Hch 2:1). Este es el período escatológico correspondiente con la "lluvia temprana" (Jl 2:23; Hch 2:17-21) o las fiestas del principio del año. Este período profético también se conoce como "los postreros días", que hace alusión al fin de la profecía de las setenta semanas destinadas para Israel según el profeta Daniel (Dn 9:24; Hch 2:17; Heb 1:2).

De acuerdo al calendario profético anual del santuario, y en la persona del sumo sacerdote, los israelitas debían enseñar y sostener la promesa de que en un año previsto por Dios, en una Pascua, en el tiempo calculado y en la ocasión festiva profetizada, Dios mismo sería el sacrificio pascual.

La iglesia remanente ya ha experimentado en el tiempo del fin la Fiesta de las Trompetas que tuvo su cumplimiento durante el gran despertar adventista del siglo XVIII, correspondiente con el mensaje de los tres ángeles de Ap 14, al fin del cumplimiento de la profecía de "tiempo, tiempos y la mitad de un tiempo" (Dn 7:25), o de los 1.260 días de Ap 12:6. También ha vivido el cumplimiento del Día de la Expiación escatológico, el 22 de octubre de 1844, al cierre del cumplimiento de la profecía de las 2.300 tardes y mañanas (Dn 8:14). Este acontecimiento marcó el comienzo del "tiempo del fin” anticipado por el profeta Daniel (Dn 8:17, 19).

Estos dos últimos cumplimientos, como todos los anteriores, se dieron en el marco de una correspondencia tipológica relativa a las fiestas cronológicas del fin del año indicadas por el calendario anual festivo del santuario israelita cercano. El período escatológico conocido como "la lluvia tardía" también está implicado en las celebraciones del fin del año ritual (Jl 2:23; Ap 18:1).

La fiesta escatológica que falta cumplirse es la Fiesta de 
los Tabernáculos. Esta fiesta representa la segunda venida de Jesús, la cual esperaban ansiosamente los tesalonicenses, pero que no podía ser posible hasta que se cumpliera el extenso calendario profético escatológico del santuario celestial, representado y controlado proféticamente por el calendario anual del santuario terrenal. Este glorioso suceso está fuera de toda fecha profética computada dada la declaración

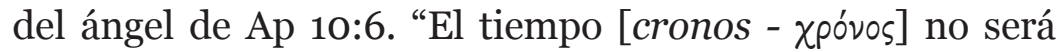
más”, es decir, el cronómetro profético se ha detenido, la cuenta profética terminó, el computo de fechas proféticas culminó el 22 de octubre de 1844. De la segunda venida de Cristo no se sabe ni el día ni la hora.

El ministerio del sumo sacerdote del santuario terrenal, enmarcado por los tiempos (cronos) de las fiestas anuales (kairós), su ministerio diario y anual, era sin duda una figura tipológica en el tiempo y en el significado o contenido de la actividad del sumo sacerdote Jesús en el santuario celestial una vez ascendido a los cielos. El mini-calendario profético y anual del santuario terrenal era una figura del macro-calendario escatológico del tiempo del fin. ${ }^{8}$

Las fiestas anuales proféticas celebradas en el santuario terrenal (espacio) como parte del calendario festivo profético (tiempo) y ministradas y convocadas por el sumo sacerdote señalaban espacios, tiempos y personajes proféticos que serían profecías, representaciones, figuras, parábolas, sombra y tipos del ministerio de Jesús en el santuario celestial (realidad, antitipo, luz, cumplimiento).

Pero sin sumo sacerdote nada de esto es posible, no hay mensaje, ni contenido ni significado, no hay ministerio ni ritual. El cautiverio babilonio (605-536 a. C.) es una muestra de la cesación del ministerio sacerdotal del santuario. Cesaron

${ }^{8}$ Alberto Timm, "El 'simbolismo en miniatura' y el principio de 'día por año’ en la interpretación profética”, Theologika 22, no. 1 (2007): 2-35. 
las fiestas, las convocaciones y los sacrificios. El ministerio diario y anual del sumo sacerdote se retoma 70 años después por permiso de Ciro y gracias a la intervención de Josué y Zorobabel, Hageo y Zacarías. Posteriormente Esdras y Nehemías restablecieron completamente el calendario de fiestas proféticas y el ministerio expiatorio, diario y anual. No es de extrañar que el nombre Hageo derive del sustantivo hebreojag que significa "festividad", haciendo referencia a (1) la necesidad espiritual de Israel de restaurar el calendario festivo profético para recuperar su identidad y conciencia de misión profética y (2) al llamado profético de Hageo en ese sentido. ${ }^{9}$ En la figura 5, se hace una representación del calendario anual del santuario terrenal y su correspondencia profético-histórica.

\section{CUMPLIMIENTO DE LAS PROFECÍAS ESPACIALES Y TEMPORALES DEL SANTUARIO TERRENAL}

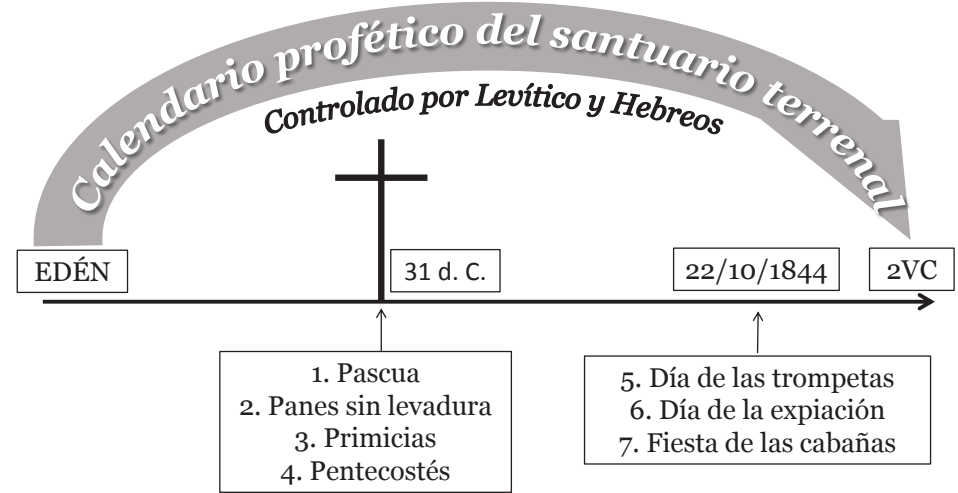

FIESTAS ANUALES PROFÉTICAS CELEBRADAS EN EL SANTUARIO TERRENAL (ESPACIO) COMO PARTE DEL CALENDARIO FESTIVO PROFÉTICO (TIEMPO) DEL SANTUARIO TERRENAL. Señalaban espacios, tiempos y personas proféticos.

Figura 5

${ }^{9}$ Raúl Quiroga, “El círculo misional de Israel”, DavarLogos 8, no. 2 (2009): 185-190. 
La localidad del santuario terrenal anticipa una universalidad del santuario celestial. Israel sería el modelo geográfico, espacial y temporal de los propósitos redentores de Dios manifestados posteriormente en la iglesia, en la humanidad y en la naturaleza de acuerdo a los tiempos previstos en la profecía. La persona del sumo sacerdote, ministro del santuario, representa el ministerio sumo sacerdotal de Cristo en el santuario celestial. De esta manera, todo el sistema del santuario israelita era una representación de la vida, muerte, resurrección, ascensión, intercesión y reinado del sumo sacerdote Cristo. En la figura 6, se representan teóricamente las implicaciones teológicas espaciales y temporales con relación al calendario profético anual del santuario israelita.

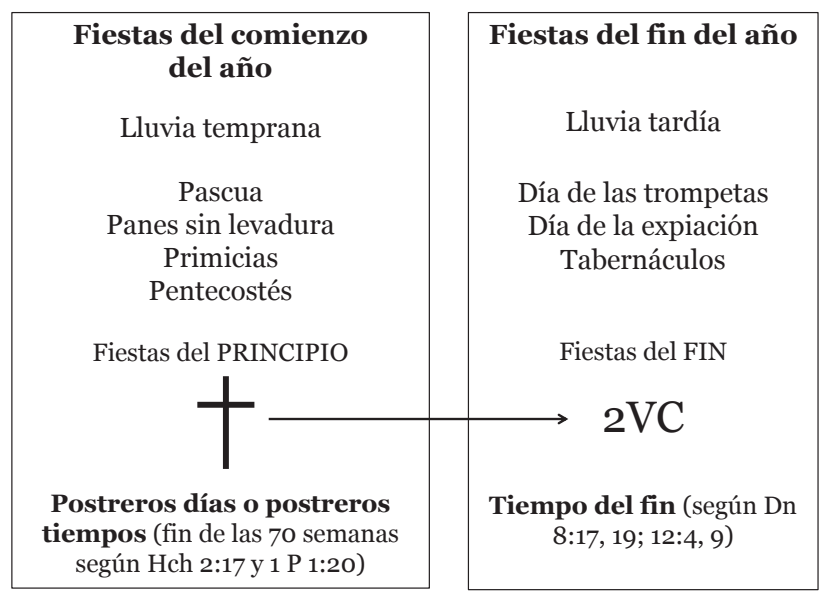

Figura 6

Hay una correspondencia profética entre el tiempo del calendario escatológico extenso del profeta Daniel y el que se repite y explica en Apocalipsis. Ambos están fundamentados en el ministerio sumo sacerdotal de Cristo en el santuario celestial; en el primero, profetizado y, en el segundo, efectivizado. 
La localidad del santuario terrenal, y lo secuencial y consecutivo de sus fiestas locales, deja su lugar al desenvolvimiento universal de la acción salvífica representada en el ministerio de Cristo en el santuario celestial, de acuerdo a las extensas y prolongadas profecías de Daniel y Apocalipsis. Las fiestas locales y cronológicas del santuario terrenal fueron un anticipo de los tiempos proféticos indicados por Daniel y Apocalipsis y cumplidos en Cristo, en la iglesia y el mundo.

Véanse estos conceptos temporales y conceptuales representados temporalmente y proféticamente en la figura 7 .

\section{CUMPLIMIENTO DE LAS PROFECÍAS ESPACIALES Y TEMPORALES DEL SANTUARIO CELESTIAL}

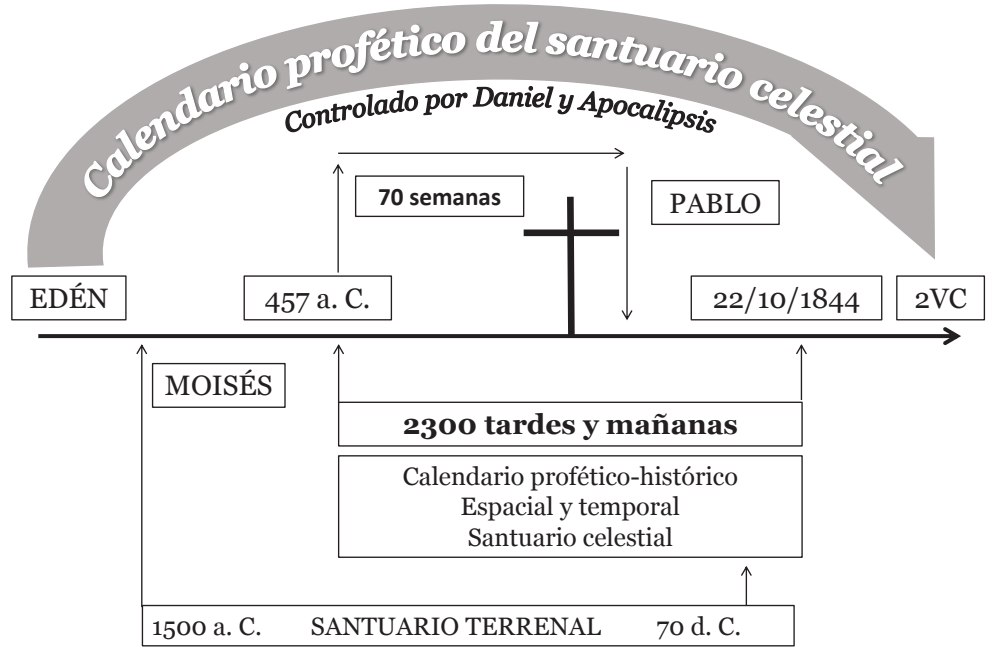

Figura 7

Daniel y Apocalipsis controlan y monitorean los tiempos y los espacios proféticos-históricos indicados para el ministerio del sumo sacerdote celestial en su santuario celestial mientras que la Torá (especialmente Levítico) y la Epístola a los Hebreos controlan y monitorean los concep- 
tos y significados teológicos y expiatorios profético-históricos señalados por el ministerio del sumo sacerdote terrenal en su santuario terrenal. Esta conceptualización se da concretamente entre el momento anticipado del sacrificio de Cristo y su regreso en gloria y majestad.

Daniel y Apocalipsis aportan respuestas a las preguntas relacionadas con los tiempos y los espacios proféticohistóricos del ministerio sumo sacerdotal (dirección conceptual: de lo terrenal a lo celestial). ${ }^{10}$ Por su parte, Levítico y Hebreos aportan respuestas a las preguntas relacionadas con los conceptos teológicos y significados expiatorios profético-históricos relacionados con la función sumo sacerdotal (dirección conceptual: de lo terrenal a lo celestial). Esta conceptualización se da concretamente entre el momento anticipado del sacrificio de Cristo y su regreso en gloria y majestad. ${ }^{11}$

Levítico (y la Torá) presentan un calendario festivo anual (años tras año) que sería como una minúscula representación del mayúsculo y extenso (siglos tras siglos) calendario profético de Daniel y Apocalipsis. El calendario local, particular, anual y exclusivo del santuario israelita se amplificaría tomando características universales, generales, inclusivas y extendido en el tiempo. ${ }^{12}$ Es como si un cono se amplificara desde su vértice inferior hacia su parte superior.

${ }^{10}$ Daniel presenta la historia con una dimensión horizontal (humana, sucesión de reinos, Dn 2 y 7) y otra vertical (intervención divina, Dn 10). Véase Arthur J. Ferch, "Authorship, Theology and Purpose of Daniel”, en Symposium on Daniel, Daniel and Revelation Committee Series 2, ed. Frank B. Holbrook (Hagerstown, MD: Review and Herald, 1986), 61-71.

${ }^{11}$ Véase Alwyn P. Salom, "Sanctuary Theology", en Issues in the Book of Hebrews, Daniel and Revelation Committee Series 4, ed. Frank B. Holbrook (Hagerstown, MD: Review and Herald, 1989), 199-218.

${ }^{12}$ Véase Timm, "El 'simbolismo en miniatura". 


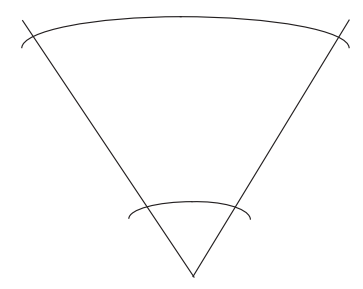

Así se definirían lo que incluye cada uno de los tres ejes teológicos profético-históricos.

Tiempo: historia profética, historia de la redención, el hilo de oro que recorre la historia de la Biblia.

Espacio: lugares geográficos proféticos, la localidad del santuario israelita, la tierra de Canaán, e Israel como pueblo de Dios, son un símbolo de la universalidad del sacrificio de Cristo, del ministerio de la iglesia y del ministerio sumo sacerdotal de Cristo en el santuario celestial.

Persona (personajes, entidades): sujetos proféticos actuantes: sumo sacerdote, imperios, pueblo de Dios.

\section{Aspectos lingüístico-teológicos relacionados con los tiempos y las épocas}

Hay una explicación lingüístico-teológica relacionada con el tiempo (cronos, jag) y la época (kairós y mo'ed) de las mismas expresada por Pablo cuando consuela a los tesalonicenses acerca de los tiempos y las ocasiones y les dice que no tienen de qué preocuparse porque Dios conducirá el desarrollo de la historia como solo Él puede hacerlo.

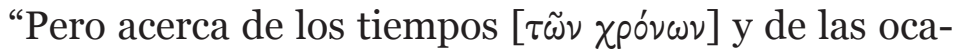
siones [xai $\tau \tilde{\omega} \nu$ xaıр $\tilde{\omega} \nu]$, no tenéis necesidad, hermanos, de que yo os escriba" (1 Ts 5:1).

En cuanto a los tiempos se refiere al cómputo de los tiempos (cronos), o tiempos cronometrados, calculados, computados. Seguramente los tesalonicenses habían sido 
instruidos y habían estudiado las profecías de tiempo de Daniel (7:25, "tiempo, tiempos y la mitad de un tiempo"; y 8:14, "hasta 2.300 tardes y mañanas") y se preguntarían cuándo sería el cumplimiento de esos cómputos proféticos, la fecha de los acontecimientos anunciados por la profecía.

En cuanto a "y de las ocasiones" (kairós) se refiere al acontecimiento en sí mismo y no tanto a la fecha. En este caso el acontecimiento o suceso, motivo de la preocupación de los tesalonicenses, era la segunda venida de Cristo en gloria y majestad, incluyendo la resurrección de los muertos y el fin del pecado. Entonces, la frase "de los tiempos y de las ocasiones" se refiere al interés de los tesalonicenses por conocer el tiempo o fecha del suceso anhelado: la segunda venida de Cristo. Véase la figura 8 en la que se aplica el uso de los dos términos para tiempo, kairós y cronos, a una semblanza del Día de la Expiación antitípico en el Apocalipsis.

\begin{tabular}{|c|c|c|c|c|}
\hline \multicolumn{5}{|c|}{ TIEMPO Y ÉPOCA EN EL APOCALIPSIS } \\
\hline $\begin{array}{c}\text { Mo'ed } \\
\text { (פוריער) } \\
\text { Tres Mo'ed }\end{array}$ & $\begin{array}{c}\text { Yom } \\
\text { Kippur }\end{array}$ & $\begin{array}{l}\text { Kairós } \\
\text { (xaıpós) }\end{array}$ & $\begin{array}{l}\text { "El tiempo está } \\
\text { cerca" } \\
\text { Ap 1:3 y 22:6 }\end{array}$ & $\begin{array}{c}\text { Tiempo como } \\
\text { época } \\
\text { Estación }\end{array}$ \\
\hline \multirow{2}{*}{$\begin{array}{l}\text { Jag (דג) } \\
\text { Siete Jag }\end{array}$} & \multirow{2}{*}{$\begin{array}{l}10^{\circ} \text { día } \\
7^{0} \text { mes }\end{array}$} & \multirow{2}{*}{$\begin{array}{l}\text { Cronos } \\
\text { (xpóvos) }\end{array}$} & $\begin{array}{c}\text { "El tiempo no será } \\
\text { más" } \\
\text { Ap 10:6 (2.300 } \\
\text { años) }\end{array}$ & \multirow{2}{*}{$\begin{array}{c}\text { Tiempo } \\
\text { cronometrado } \\
\text { computado } \\
\text { contado } \\
\text { Suceso } \\
\text { Evento }\end{array}$} \\
\hline & & & $\begin{array}{c}\text { "Venido el } \\
\text { cumplimiento del } \\
\text { tiempo" } \\
\text { Gá 4:4 (70 } \\
\text { semanas) }\end{array}$ & \\
\hline
\end{tabular}

Figura 8 
A continuación se mencionan algunos ejemplos bíblicos para ilustrar la diferencia entre tiempo cronometrado,

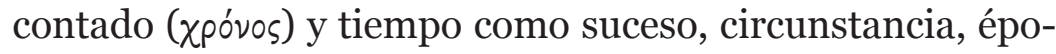
ca, momento (xaıpós).

\section{Tiempo, época o circunstancia (xalpós) $)^{13}$}

(1) "Éstas son las fiestas solemnes de Jehová, las convocaciones santas, a las cuales convocaréis en sus tiempos [xalpós]" (Lv 23:4). Una referencia al calendario profético anual del santuario terrenal, monitoreado, conducido y convocado por el sumo sacerdote y su equipo de ministros territoriales, los levitas.

(2) "Y llegó el tiempo [xal o xaıpòs દ̇óón], y los santos recibieron el reino" (Dn 7:12). Cuando se cumpla la profecía correspondiente de tiempo coincidente con la fiesta tipológica, el reino será dado a los santos de Dios.

(3) "El tiempo [ó xaıpós] se ha cumplido, y el reino de Dios se ha acercado; arrepentíos, y creed en el evangelio" (Mr 1:15). Se afirma que la época ha llegado y se han cumplido las circunstancias proféticas.

(4) Pero "mi tiempo [ó xaıpòs] aún no ha llegado" (Jn $7: 6,8)$. Se refiere a la época, el momento o las circunstancias del sacrificio.

(5) "Y de una sangre ha hecho todo el linaje de los hombres, para que habiten sobre toda la faz de la tierra; y les ha prefijado el orden de los tiempos [xalpoùs], y los límites de su habitación" (Hch 17:26). Los tiempos y circunstancias referidos a la humanidad están monitoreados por Dios con un propósito redentor.

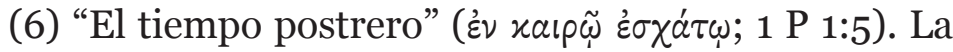
época de una salvación futura.

${ }^{13}$ Barbara Friberg, Timothy Friberg y Neva F. Miller, Analytical Lexicon of the Greek New Testament (Grand Rapids, MI: Baker, 2000), palabra n ${ }^{0} 14655$. 


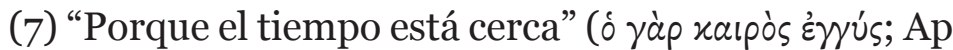
1:3). Un recordativo oportuno de que se acerca el acontecimiento máximo que espera la historia: la segunda venida de Cristo en gloria y majestad.

(8) El tiempo como época, circunstancia anunciada en el libro de Daniel siempre es traducido xaıpós en la LXX (Dn $7: 25 ; 8: 17,19 ; 12: 4)$.

\section{Tiempo para cronometrar, contabilizar, computar, contar (xaıpós) $)^{14}$}

(1) "Habían también quitado a las otras bestias su dominio, pero les había sido prolongada la vida hasta cierto

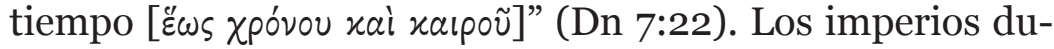
ran la cantidad de tiempo que Dios les concede, no todo el tiempo que ellos quieren.

(2) "El muda los tiempos y las edades [xalpoìs xai

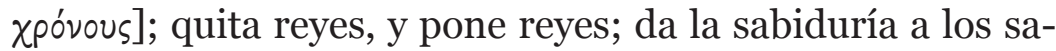
bios, y la ciencia a los entendidos" (Dn 2:21).

(3) "Pero cuando se acercaba el tiempo [ó xpóvos] de la promesa, que Dios había jurado a Abraham, el pueblo creció y se multiplicó en Egipto" (Hch 7:17). Se habían cumplido los 400 años de esclavitud profetizados en Gn 15:13.

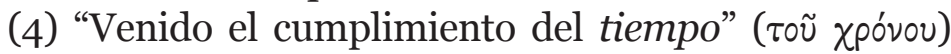
(Gá 4:4) referido al tiempo cronometrado exacto en la profecía del momento del nacimiento de Cristo en Belén. El espacio geográfico y el tiempo del nacimiento del Mesías estaban profetizados con exactitud meridiana (Mi 5:2; Dn 9:24-27).

(5) "Pero manifestado en los postreros tiempos" ( $\dot{\varepsilon} \pi$ '

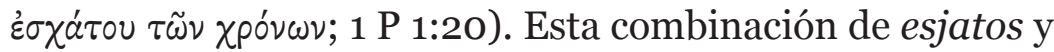
cronos podría traducirse como "la última cuenta" que se hizo para Israel, las 70 semanas, período durante el que na-

${ }^{14}$ Ibíd., palabra no 28793. 
ció Cristo. Se refiere al fin de las 70 semanas para Israel o a la semana del Mesías Príncipe (año 31, 34 d. C. y, específicamente, a la caída de Jerusalén en el 70 por la invasión de Tito, general del emperador romano Vespasiano).

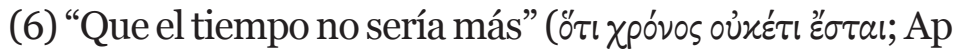
10:6). Terminan las profecías de tiempo computable. Después del 22 de octubre de 1844 no hay más períodos de tiempo profético. Las 2.300 tardes y mañanas han terminado de contarse.

\section{Gráfico de la combinación profética de tiempo kairós y cronos}

Se presenta en el cuadro que sigue la representación temporal e histórica, temática y teológica del "postrero tiempo" y del "tiempo del fin" siempre sobre la base de los dos términos griegos referidos a "tiempo": xaıpós (época)

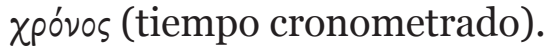

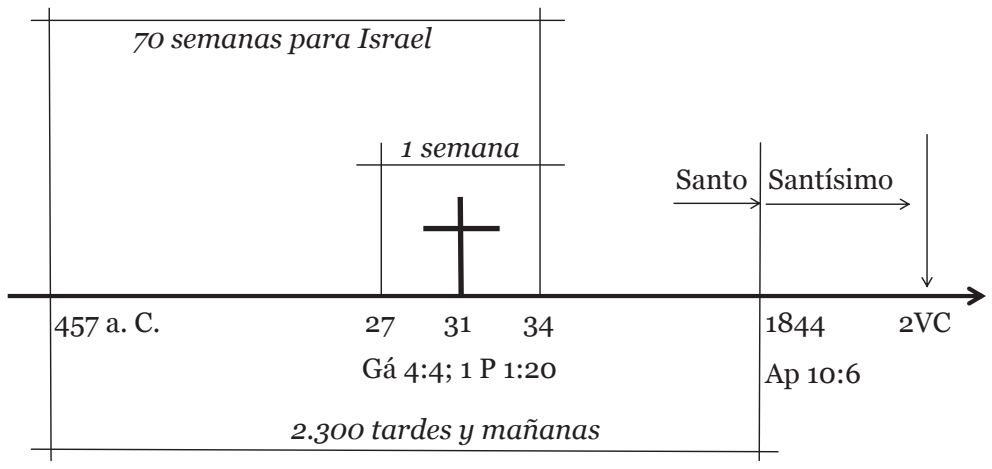

Las fiestas del comienzo del año o los postreros días son referidas a las 70 semanas determinadas para Israel (34 d. C.). Las fiestas del fin del año o el tiempo del fin señalan el fin de los 2.300 tardes y mañanas para el pueblo de Dios en toda la tierra (iglesia) (22/10/1844). Cada fiesta representaría un período profético. 
La tarea del sumo sacerdote hacia adentro del santuario consistía en mantener vigente ante Israel el calendario anual de festividades. Debía monitorear estos tiempos proféticos o convocatorias simbólicas que eran un tipo del calendario real e histórico de redención.

Los levitas eran asistentes externos del sumo sacerdote del santuario, pastores del rebaño de Israel, que vivían en las ciudades de refugio o en las ciudades asignadas. Era su tarea ministerial mantener la vinculación del pueblo con el calendario festivo del santuario. Ellos respondían a la convocatoria del sumo sacerdote y acompañaban al pueblo en los tres viajes anuales. Los levitas eran los maestros de Israel. Su tarea era enseñar la ley de Moisés, instruir acerca del plan de redención, mantener la espiritualidad del pueblo ayudándoles a sostener su vinculación pactual con Jehová. Ellos ayudaban al pueblo a sostener el ministerio del santuario con los diezmos y ofrendas (plan de benevolencia sistemática). Además, eran los jueces del pueblo; los asuntos difíciles de solucionar se los llevaban al sumo sacerdote quien a través de Urim y Tumim resolvían las cuestiones complicadas. Los levitas también eran los músicos de Israel que dirigían los coros y las orquestas de Israel para mantener vigente la alabanza al Dios de Israel. El tema de su alabanza siempre fue la Ley de Moisés. Su resultado testimonial e histórico son los Salmos.

Los nazareos (hombre o mujer según Nm 6:2) eran asistentes circunstanciales y momentáneos del sumo sacerdote y de los levitas. Posiblemente las mujeres violentadas por los hijos de Elí hayan sido nazareas. Había mujeres que hacían guardia o ministraban en el tabernáculo del testimonio (Éx 38:8). Por un voto personal y por voluntad propia, los nazareos decidían servir en el santuario y ser asistentes espirituales de Israel a través del ministerio del sumo sacerdote. Un nazareo paradigmático fue Sansón aunque su interés personal no fue servir a través del santuario ni contribuir a la espiritualidad de Israel. 
Las guerras y los momentos ocasionales de disipasión sensual fueron su ocupación primordial. Los sacerdotes y levitas eran nazareos (Lv 21:12) y servían en el santuario por obligación genética ya que pertenecían a la tribu de Leví, separada por Dios para tal ministerio. Los nazareos no tenían vinculación genética con Leví pero servían voluntariamente en el santuario.

Este equipo ministerial, sumo sacerdote y levitas, estaba ligado al santuario en el tiempo (tres convocaciones anuales), en el espacio (lugar geográfico del santuario y sus espacios proféticos: altar en el lugar santo y arca en el lugar santísimo). La persona representativa y responsable de este calendario profético era el sumo sacerdote ungido.

En la figura 9, se representa temporal y lingüísticamente la cantidad de fiestas del santuario terrenal pero trasladada al extenso calendario profético de Daniel y Apocalipsis. Son tres convocaciones, viajes o mo'ed para celebrar siete festividades o jag ( $\mathrm{Lv} 23$ ). Hay dos convocaciones al principio del año y una al final del año.

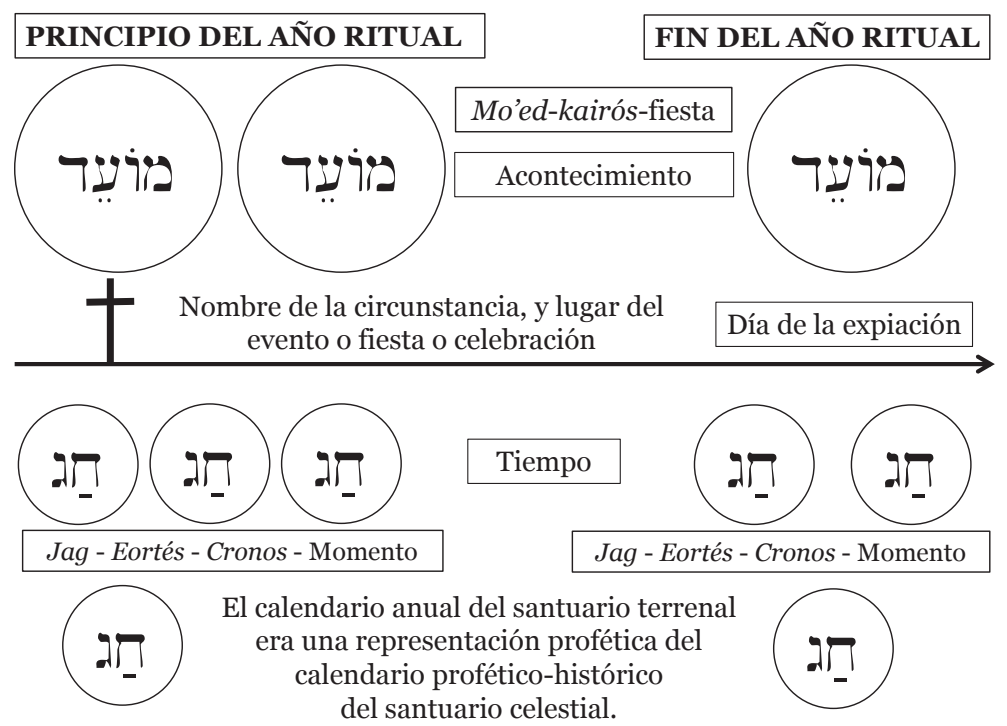

Figura 9 
Todas las fiestas del santuario giran en torno a dos puntos focales, el altar y el arca, como los focos de una elipsis. El personaje central sigue siendo siempre el sumo sacerdote quien monitorea, controla, supervisa los tiempos del santuario y convoca al pueblo a las fiestas propias de cada tiempo señalado. Véase la siguiente tabla.

\begin{tabular}{|c|c|}
\hline \multicolumn{2}{|c|}{ Sumo sacerdote en el santuario } \\
\hline Ministerio diario & Ministerio anual \\
\hline Altar-Arca & Altar-Arca \\
\hline Sacrificio-Ley & Sacrificio-Ley \\
\hline Sangre & Sangre \\
\hline Expiación diaria & Expiación anual \\
\hline Intercesión diaria & Intercesión final \\
\hline Perdón-Obediencia & Perdón-Obediencia \\
\hline Justificación-Santificación & Justificación-Santificación \\
\hline Sustentación diaria & Sustentación eterna \\
\hline
\end{tabular}

El calendario anual profético de Israel monitoreado por el sumo sacerdote terrenal se superpone al extenso calendario escatológico y profético de Daniel y Apocalipsis monitoreado por el sumo sacerdote celestial. Y este mecanismo temporal y espacial monitoreado por el sumo sacerdote terrenal primero, y después por el sumo sacerdote celestial, se ha insertado en la estructura del libro de Apocalipsis. Esta intención exegética sustentada por la hermenéutica del santuario, puede explicar la estructura histórico-profética de Apocalipsis.

El libro espejo de Apocalipsis, Daniel, sustenta una estructura histórico-profética. La historia o testimonio de la profecía se relata primero (Dn 1-6) y después la profecía misma (Dn 7-12). Parece que Apocalipsis sigue la misma metodología profética: Ap 1-9 relata el testimonio de la pro- 
fecía, más que nada referido a lo que ya se ha cumplido con respecto del pueblo de Dios, después, Ap 10-22 anticipa lo que falta cumplirse. Véase la figura 10.

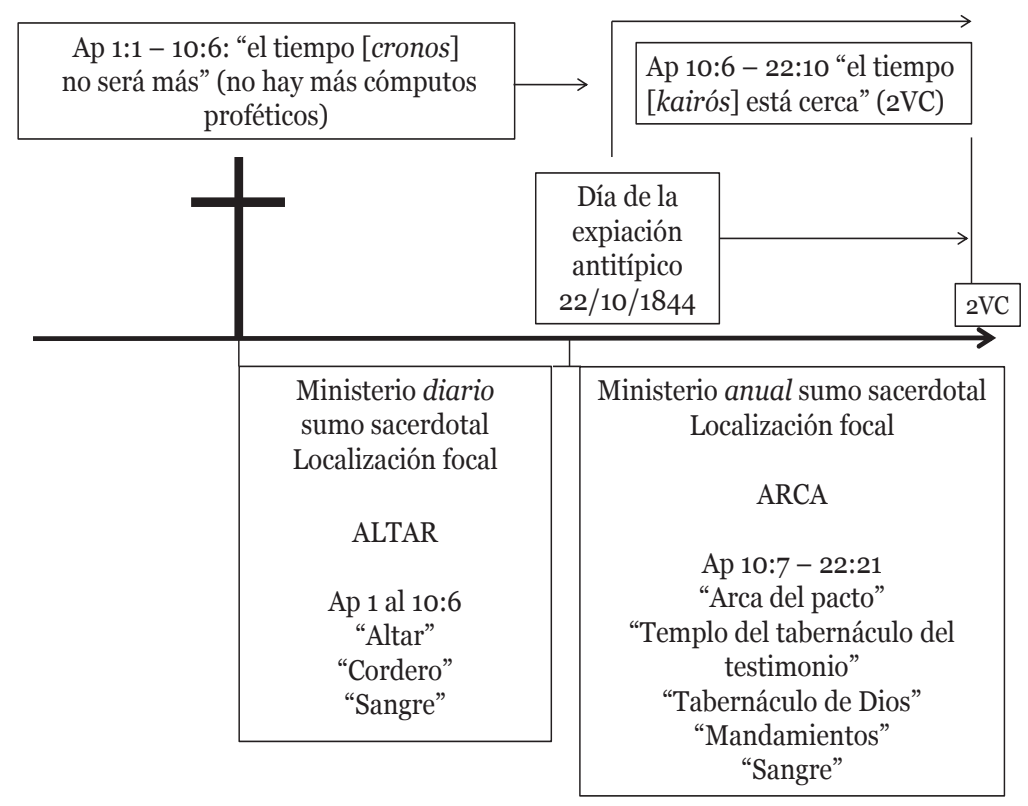

Figura 10

Esta metodología exegética, es decir la superposición de los dos calendarios del santuario anual-corto para el terrenal y escatológico-extenso para el celestial, y su aplicación a la estructura de Apocalipsis, se basa en que la perspectiva focal de Apocalipsis se centra en un momento profético escatológico: el día antitípico de la expiación, el fin de las 2.300 tardes y mañanas, el 22 de octubre de 1844 .

Este fenómeno temporal interpretativo se da porque ese sería el momento histórico profetizado temporal y espacialmente con respecto de las fiestas del santuario para revelar el último misterio de Dios a la iglesia y a la humanidad: el 
comienzo del tiempo del fin y la alarma correspondiente por la extrema urgencia de anunciar que la historia de la humanidad se termina (mensaje de los tres ángeles, Ap 14:6-14).

El sumo sacerdote celestial, al igual que el sumo sacerdote en el Día de la Expiación típico, está por levantarse y poner fin a su ministerio de intercesión y a su obra expiatoria. Está por exclamar nuevamente: "Consumado es". A partir de ese momento histórico-profético se entiende todo el libro de Apocalipsis. Véase la figura 11.

\section{RELACIÓN ENTRE DANIEL Y APOCALIPSIS} EL SERVICIO DIARIO Y EL DÍA DE LA EXPIACIÓN

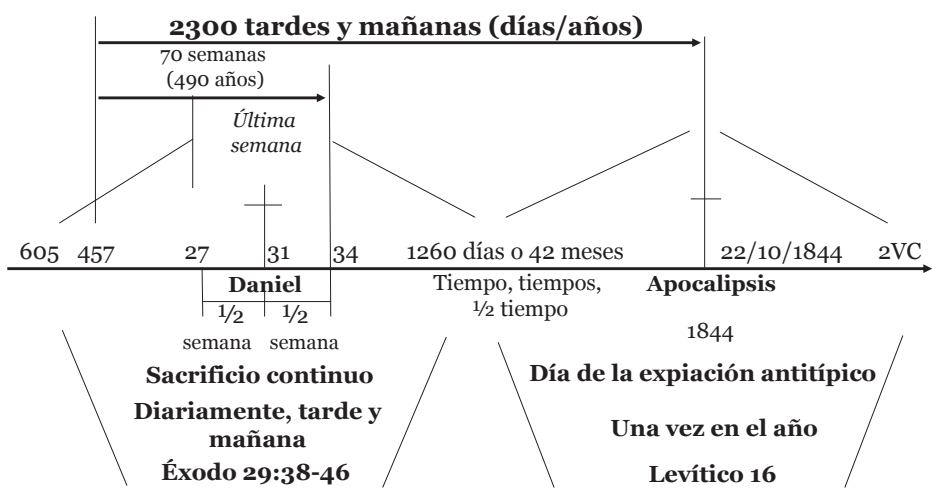

Figura 11

El campo semántico que forman kairós y cronos genera una comprensión interpretativa (hermenéutica) del Apocalipsis. Esas palabras son de corte temporal y ambiental relacionadas con los tiempos y los espacios del santuario. Su uso particular es además una justificación lingüística y literaria (exégesis) para sostener que la temporalidad (convocaciones anuales) y la espacialidad (lugar santo/altar y lugar santísimo/arca), monitoreada por el sumo sacerdote en el santuario terrenal (tipo) y la supervisión antitípico del sumo sacerdote del santuario ce- 
lestial (antitipo) sostienen una hermenéutica del Apocalipsis relacionada con los tiempos, espacios y personas del santuario. La realidad divina y celestial se hace una con la realidad humana y terrenal a través de la conexión establecida entre el santuario celestial y el terrenal. Nada sucede en la tierra que no incida en el cielo y nada sucede en el cielo que no tenga su impacto en la tierra. Los salmos exponen que el santuario del cielo y el de la tierra son uno solo. Es difícil determinar por los salmos mismos si Dios habita en el santuario del cielo o en el de la tierra. Uno es parte del otro y Dios reina en su santuario sin aclarar en cuál (Sal 11 y 20; Is 66:1). ${ }^{15} \mathrm{~A}$ través de las significaciones expuestas por la simultaneidad existencial del santuario celestial y del terrenal, la realidad del cielo y de la tierra se transforma en una única y sola realidad. El puente de unión queda establecido para siempre y ese puente parece ser el santuario en su manifestación terrenal y celestial.

En la figura 12, se detallan las palabras del Apocalipsis que generan en ese libro la ambientación del santuario.

Altar (sacrificio), sangre, fuego, Cordero, incienso.

Palabras que representan el ministerio de intercesión (diario, continuo) del Sumo Sacerdote (terrenal-celestial). Lugar santo. Ministerio diario. Intercesión.

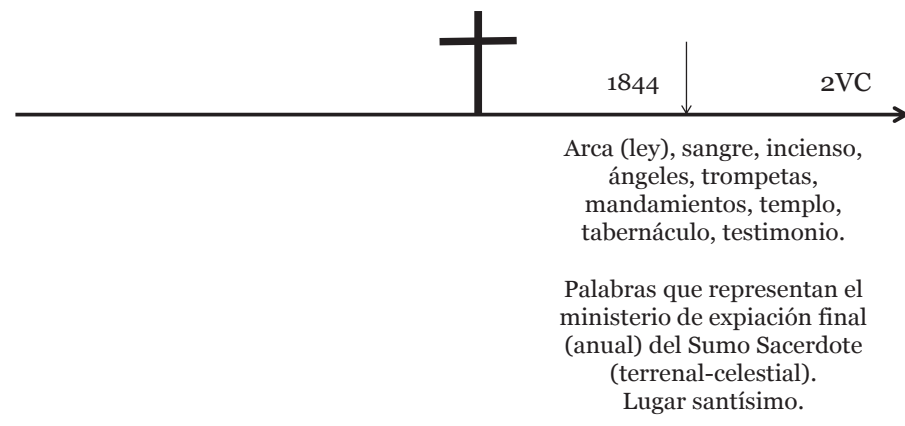

Figura 12

${ }^{15 N i e l s-E r i k ~ A n d r e a s e n, ~ " T h e ~ H e a v e n l y ~ S a n c t u a r y ~ i n ~ t h e ~ O l d ~ T e s t a-~}$ ment", en The Sanctuary and the Atonement, 63-80. 


\section{Conclusiones}

En el Apocalipsis se da una interrelación entre el altar y el arca por: 1) El trasfondo de un carácter único de la teología adventista: perdón en el altar del sacrificio más obediencia a la ley de Dios. La fórmula redentora sería ser perdonados para obedecer, justificados para ser santificados; y el movimiento sería de la fe del perdón a la misma fe de la obediencia, de la justicia de la fe a la justicia de las obras, de la causa al efecto.

2) La evidencia de los tiempos proféticos cronometrados, o época de los sucesos proféticos ("tiempo, tiempos y la mitad de un tiempo", 1.260 días o 42 meses) y su conexión con las 2.300 tardes y mañanas de Dn 8:14.

3) Un reflejo o eco de los tiempos como sucesos o eventos, nombre de los eventos (Pascua, Pentecostés, Fiesta de las Trompetas, Día de la Expiación).

4) Un reflejo o eco del ministerio diario y anual del sumo sacerdote en el santuario terrenal.

5) Una evidencia de la relación espacial y temporal que señala al Día de la Expiación antitípico y a la segunda venida de Jesús en la persona del sumo sacerdote celestial.

6) Una relación teológica de las personas o sujetos proféticos involucrados en el cumplimiento de la profecía del santuario (sumo sacerdote, Dios, Espíritu Santo, ángeles, iglesia, anticristo, bestias, naciones).:응

Raúl A. Quiroga raulalbertoquiroga@gmail.com Universidad Adventista del Plata Entre Ríos, Argentina

Recibido: 11/06/2016 Aceptado: 20/02/2017 